\title{
Article \\ High Frequency Electromagnetic Shielding by Biochar-Based Composites
}

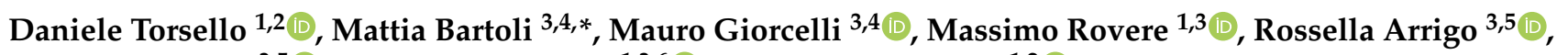 \\ Giulio Malucelli ${ }^{3,5}\left(\mathbb{D}\right.$, Alberto Tagliaferro ${ }^{1,3,6}\left(\mathbb{D}\right.$ and Gianluca Ghigo ${ }^{1,2}(\mathbb{D}$ \\ 1 Politecnico di Torino, Department of Applied Science and Technology, C.so Duca degli Abruzzi 24, \\ 10129 Turin, Italy; daniele.torsello@polito.it (D.T.); massimo.rovere@polito.it (M.R.); \\ alberto.tagliaferro@polito.it (A.T.); gianluca.ghigo@polito.it (G.G.) \\ 2 Istituto Nazionale di Fisica Nucleare, Sez. Torino, Via P. Giuria 1, 10125 Turin, Italy \\ 3 Consorzio Interuniversitario Nazionale per la Scienza e Tecnologia dei Materiali (INSTM), Via G. Giusti 9, \\ 50121 Florence, Italy; mauro.giorcelli@polito.it (M.G.); rossella.arrigo@polito.it (R.A.); \\ giulio.malucelli@polito.it (G.M.) \\ 4 Center for Sustainable Future Technologies_CSFT@POLITO, Via Livorno 60, 10144 Torino, Italy \\ 5 Politecnico di Torino, Department of Applied Science and Technology, Viale Teresa Michel 5, \\ 15121 Alessandria, Italy \\ 6 Faculty of Science, Ontario Tech University, 2000 Simcoe Street North, Oshawa, ON L1G 0C5, Canada \\ * Correspondence: mattia.bartoli@politecnico.it
}

check for updates

Citation: Torsello, D.; Bartoli, M.; Giorcelli, M.; Rovere, M.; Arrigo, R.; Malucelli, G.; Tagliaferro, A.; Ghigo, G. High Frequency Electromagnetic Shielding by Biochar-Based Composites. Nanomaterials 2021, 11, 2383. https://doi.org/10.3390/ nano11092383

Academic Editors: Xuchun Gui, Jeremy Sloan and Daryoosh Vashaee

Received: 14 July 2021

Accepted: 11 September 2021

Published: 13 September 2021

Publisher's Note: MDPI stays neutral with regard to jurisdictional claims in published maps and institutional affiliations.

Copyright: (c) 2021 by the authors. Licensee MDPI, Basel, Switzerland. This article is an open access article distributed under the terms and conditions of the Creative Commons Attribution (CC BY) license (https:/ / creativecommons.org/licenses/by/ $4.0 /)$.

\begin{abstract}
We report on the microwave shielding efficiency of non-structural composites, where inclusions of biochar-a cost effective and eco-friendly material-are dispersed in matrices of interest for building construction. We directly measured the complex permittivity of raw materials and composites, in the frequency range $100 \mathrm{MHz}-8 \mathrm{GHz}$. A proper permittivity mixing formula allows obtaining other combinations, to enlarge the case studies. From complex permittivity, finally, we calculated the shielding efficiency, showing that tailoring the content of biochar allows obtaining a desired value of electromagnetic shielding, potentially useful for different applications. This approach represents a quick preliminary evaluation tool to design composites with desired shielding properties starting from physical parameters.
\end{abstract}

Keywords: biochar; carbon-based composites; electromagnetic shielding; high frequency

\section{Introduction}

There is an increasing interest in shielding electronic devices and communication instruments against electromagnetic (EM) radiation, in order to improve their efficiency and lifetime. This requirement is sometime extended to entire buildings. In fact, there are particular places that should be well protected against EM interference, e.g., those dedicated to the health sector for applications, such as imaging or tomography, working with microwave- and millimeter-wave devices. In this cases, usually, shielding materials are applied as a coating on wall surfaces. However, the use of shielding elements directly mixed with currently used building materials has been considered only recently, and could represent a sustainable route, especially if the additional materials are eco-friendly and cost-effective [1,2].

The main drawback of EM-shielding materials is related to the drop of mechanical properties due to high filler concentration, as observed by Wen et al. [3]. Accordingly, coating approaches and non structural materials have been used for EM-shielding applications [4]. This opened the way for the production of materials that do not require superior mechanical properties, but only a great shielding efficiency.

The shielding efficiency (SE) of a material depends on its intrinsic properties, i.e., conductivity $\sigma$ and permittivity $\varepsilon$. Thus, due to high $\sigma$, metals are well suited for many 
EM-shielding applications, but they also have disadvantages, such as heavy weight [5], corrosion propensity [6], mechanical stiffness, and high cost [7]. When metal coatings become unpractical, one can consider conducting composites, showing light weight, flexibility, and low cost [8,9]. Further advantages of this approach include the tunable shielding response, depending on preparation and/or conducting inclusions concentration, and possibly manufacturing of finished products by coating or 3D printing. Among the materials with these properties, promising for EM-shielding applications, carbon-based composites recently emerged as a reliable solution. In particular, an eco-friendly material derived from waste, matching these requirements, is biochar. Biochar is a carbonaceous material produced by thermal treatment of biomass (e.g., from agricultural or food waste), showing good enough properties to be considered as a practical alternative to the use of other more performing carbon-based materials, such as graphene or carbon nanotubes, which are much more expensive and require complex synthesis [10]. SE of carbonaceous-based composite materials reported in literature (a wide selection of which is shown in Table 1) are deeply affected by the intrinsic properties of the fillers, that dominate over matrix properties. High tech, expensive, fillers, such as carbon nanotubes (for which extensive details can be found in Reference [11]) and nanofibers, showed the best results, but high loading levels of biochar are expected to reach comparable performances for a much cheaper price, as necessary in fields where large volumes are required.

Table 1. Representative values of SE of different composites with carbonaceous fillers.

\begin{tabular}{|c|c|c|c|c|}
\hline Material & Thickness (mm) & SE (dB) & Frequency (GHz) & Ref. \\
\hline Flexible graphite flakes & not reported & 130 & 1.0 & [12] \\
\hline 15 wt. $\%$ of Carbon nanotubes into ABS matrix & 1.1 & 50 & 8.2 & [13] \\
\hline 15 wt. $\%$ of carbon nanofibers into ABS matrix & 1.1 & 35 & 8.2 & [13] \\
\hline 15 wt. $\%$ of carbon black into ABS matrix & 1.1 & 21 & 8.2 & [13] \\
\hline 18 wt. $\%$ of carbon black into EVA matrix & 2 & 18 & 8.2 & [14] \\
\hline 3 layers of epoxy laminated carbon fibers & 3 & 21 & 1.0 & [15] \\
\hline $0.4 \mathrm{wt} . \%$ of carbon fibers in cementitious matrix & 180 & 42 & 1.0 & [16] \\
\hline 8 wt. \% of commercial biochar in cementitious matrix & 180 & 15 & 10.0 & {$[2]$} \\
\hline $20 \mathrm{wt} . \%$ of sludge biochar in cementitious matrix & 180 & 10 & 10.0 & [17] \\
\hline 80 wt. $\%$ of biochar in UHDPE matrix & 140 & 49 & 5.0 & [18] \\
\hline
\end{tabular}

A rich and interesting area of research focuses on understanding the origins of EM losses and shielding in different fillers, in order to optimize and engineer them. Magnetic effects are predominant when metallic inclusions are employed [19], and their efficiency can be engineered by changing shape, size, and encapsulation [20]. In other cases, where no metallic particles are added -as in the present case-, the main contribution to shielding comes from the conductivity of the inclusions in the insulating matrix. In this field, carbon materials have a very important role due to the extremely wide tunability of their properties [21], that makes this class of materials pivotal for applications that range from EM shielding to next-generation sensors and devices [22,23]. In the specific case of biochar, several aspects intervene due to its intrinsically disordered nature and to the large range of graphitization degrees that can be obtained depending on its preparation procedure [24]. However, the main contributions to EM shielding in such materials are expected to stem from migration and hopping conductance [25]. As a result of these mechanisms, it turns out that high-carrier-mobility carbon-based fillers are extremely promising and versatile for shielding composites [26]. In addition to the understanding of the mechanisms of EM losses in specific materials, an important aspect is the possibility to quickly estimate the behavior of a composite starting from the physical properties of its matrix and filler. This is a preliminary step needed to focus experimental efforts mainly on the most promising combinations.

In this work, we discuss about the EM-shielding properties of composites made of biochar inclusions dispersed into non-structural materials of interest for building construc- 
tion. Cement is one of them, since cement-based materials, e.g., paste, mortar, and concrete, are currently widely employed not only for their mechanical properties but also because they are durable and economical, as well as could be easily applied as high filled layer in pre-existent structures. Other materials potentially useful for coatings in buildings are epoxy resins and high-density polyethylene (HDPE). We performed a microwave characterization of biochar composites based on these materials, yielding their complex permittivity. We evaluated the SE of the measured materials and composites, and of other combinations obtained by suitable mixing rules, allowing us to simulate the electromagnetic behavior of composites as a function of biochar loading.

Overall, the promising potential of biochar as low-cost and eco-friendly material to improve shielding to EM interference in buildings is demonstrated, and the methodology proposed in this work is shown to provide a useful preliminary approach to design composites with desired EM-shielding properties.

\section{Materials and Methods}

\subsection{Biochar, Matrices, and Composites Preparation}

The biochar employed in this study (OSR 550: C $68.9 \pm 2.3$ wt.\%, H $1.82 \pm 0.22$ wt.\%, $\mathrm{N} 1.59 \pm 0.22$ wt.\%, P $0.29 \pm 0.08$ wt.\%, K $2.86 \pm 0.26$ wt.\%, total ash $19.5 \pm 0.9$ wt.\%, metal content in the ppm range) is derived from oil-seed and was purchased from UK Biochar Research Center, where it was produced using a pilot-scale rotary kiln pyrolysis unit [27] with highest treatment temperature $550{ }^{\circ} \mathrm{C}$. We have shown that biochar powders can be thermally treated to tune their conductivity and permeability, and then dispersed in a suitable matrix to obtain convenient mechanical properties [24,28]. For this reason, the biochar was then annealed at $1500{ }^{\circ} \mathrm{C}$ by using a vacuum electric furnace (Pro.Ba., Cambiano, Italy) under argon atmosphere (99.99\% purity, controlled pressure 550 mbar) with a heating rate of $150{ }^{\circ} \mathrm{C} / \mathrm{h}$, a maximum temperature dwell time of $30 \mathrm{~min}$, followed by cooling to room temperature with the same rate used for heating [29]. Biochar-based epoxy composites were prepared according to Bartoli et al. [30], employing a two components Bis phenol A (BPA) diglycidyl resin system purchased from CORES (Cores epoxy resin, LPL). Biochar was mechanically pulverized and subsequently dispersed into the epoxy monomer (biochar loading: $25 \mathrm{wt}$ \%) using a tip ultrasonicator apparatus (Sonics Vibra-cell) for $15 \mathrm{~min}$, employing a pulsed mode with cycles of $20 \mathrm{~s}$ (alternated by $10 \mathrm{~s}$ pauses) to allow a better heat diffusion and avoid an excessive temperature rise. Further ultrasonication for 2 min was performed after the addition of the curing agent. Then, the mixture was left into the molds for $16 \mathrm{~h}$ at room temperature. A final thermal curing was performed using a ventilated oven (I.S.C.O. Srl "The scientific manufacturer") at $70{ }^{\circ} \mathrm{C}$ for $6 \mathrm{~h}$.

Cement (Portland Type 152.5 R) was purchased from Italcementi S.p.A., Bergamo, Italy. Samples were prepared by mixing neat cement with water and cured in water for $24 \mathrm{~h}$ at $80{ }^{\circ} \mathrm{C}$ in $90 \%$ humidity atmosphere.

The employed HDPE has the trade name Lupolen 4261AG from Lyondell Basel. Its main characteristics are: melt flow rate $\left(190{ }^{\circ} \mathrm{C} / 21.6 \mathrm{~kg}\right)=6.0 \mathrm{~g} / 10 \mathrm{~min}$, density $=0.945 \mathrm{~g} / \mathrm{cm}^{3}$, and melting temperature in the range $120-140{ }^{\circ} \mathrm{C}$. Specimens were obtained by compression molding, using a laboratory press (Collin Teach Line 200T), working at $220^{\circ} \mathrm{C}$, under a pressure of 100 bar for $2 \mathrm{~min}$.

\subsection{Biochar Characterization}

Raman spectra were collected using a Renishaw inVia (H43662 model, Gloucestershire, UK) equipped with a green laser line $(514 \mathrm{~nm})$, in the range from $500 \mathrm{~cm}^{-1}$ to $3500 \mathrm{~cm}^{-1}$. X-ray diffraction (XRD) analyses were performed by using a Panalytical X'PERT PRO PW3040/60 diffractometer, with $\mathrm{Cu} \mathrm{K} \alpha$ radiation at $40 \mathrm{kV}$ and $40 \mathrm{~mA}$, Panalytical BV, Almelo, The Netherlands. The spectra were obtained from biochar powder in the $2 \theta$ range from $15^{\circ}$ to $90^{\circ}$ with a step size of $0.013^{\circ}$. 


\subsection{Microwave Characterization}

The SE of several biochar-based composites has been assessed starting from a microwave characterization in the frequency range $100 \mathrm{MHz}-8 \mathrm{GHz}$ of cement, HDPE and epoxy matrices, and biochar-epoxy composites. This frequency range covers the bands from UHF to C, used for communications, including GPS, Wi-Fi, and Bluetooth devices, mobile phones, and radar systems.

In order to achieve a preliminary characterization of a large set of biochar-based composites, we employed a multi-step approach, summarized here and detailed below: (i) we measured the complex dielectric constant of all the matrices, (ii) we determined the dielectric constant of biochar as an inclusion material (which, in principle, might be different from the starting biochar powders) by measuring several concentrations of a specific composite (epoxy + biochar) and employing a proper mixing rule, and (iii) we applied the same rule (inversely) to deduce the effects of biochar addition to the other matrices.

The microwave measurements were based on a two-port transmission line technique in a cylindrical coaxial cell (EpsiMu toolkit [31]) connected to a Vector Network Analyzer. The sample was inserted into the cell as a spacer between inner and outer conductors, with diameters of 0.6 and $1.3 \mathrm{~cm}$, respectively. The EM properties of the sample were then extracted by de-embedding and by using a Nicolson-Ross-Weir transmission/reflection algorithm $[32,33]$. The output of measurements is the complex permittivity of the material, $\varepsilon=\varepsilon^{\prime}-j \varepsilon^{\prime \prime}$, where $j=\sqrt{-1}$. An example is given in Figure 1, where the real part of permittivity $\varepsilon^{\prime}$ and loss tangent $\tan \delta=\varepsilon^{\prime \prime} / \varepsilon^{\prime}$ are shown for epoxy and for an epoxy$25 \mathrm{wt} . \%$-biochar composite. The oscillations in the measured values are due to the geometry of the measurement cell and are common in measurement techniques based on microwave transmission lines. The value of $\tan \delta$ measured for pure epoxy is in quite good agreement with those commonly reported, especially at higher frequencies where spurious oscillations are smaller. At lower frequencies, the measurement is less precise but still in an acceptable range. Moreover, this uncertainty has a quite small effect on the conclusions drawn in this study, that are based on general trends and not on specific low frequency values.

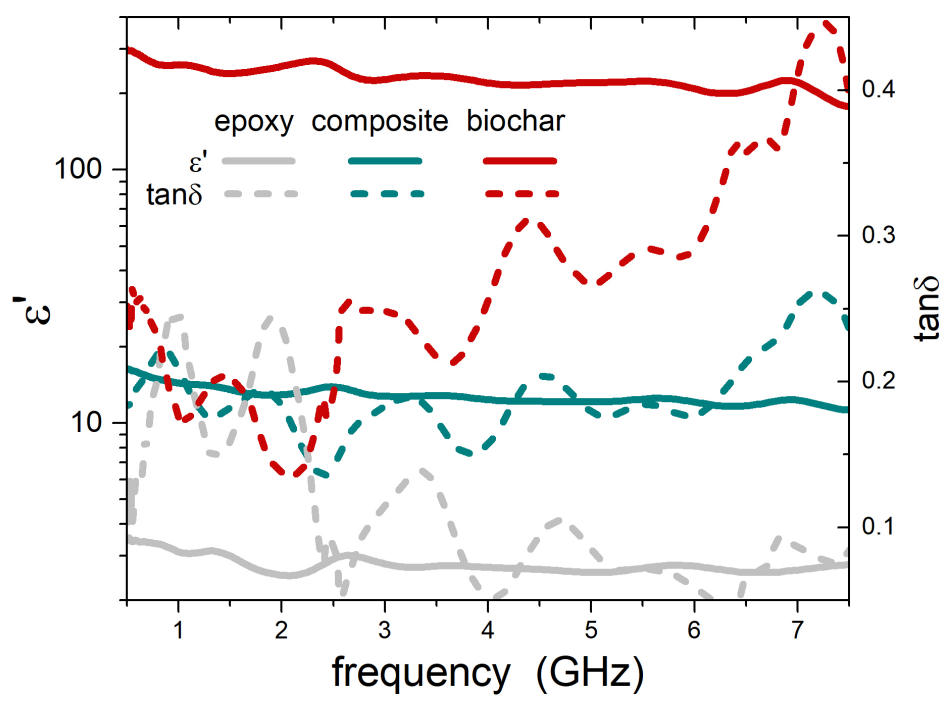

Figure 1. Real part of the permittivity (logarithmic scale, on the left) and loss tangent (linear scale, on the right) for analyzed epoxy and epoxy-25 wt.\%-biochar composite (measured), and for biochar inclusions alone (calculated).

Once the properties of matrix and composite are obtained, it is also possible to extract the EM properties of the biochar inclusions alone, by using a proper mixing rule, expressing the overall permittivity $\varepsilon$ as a function of the complex permittivity of each constituents $\left(\varepsilon_{m}\right.$ for the matrix and $\varepsilon_{b}$ for biochar inclusions) and volume fraction $f$ of the filler [24]. To this aim, several approaches have been reported, depending on the shape of inclusions. We used the Looyenga rule, which does not involve any assumption about the geometry of the 
inclusion particles [34], and that demonstrated a very good matching with experimental data in similar cases [35] :

$$
\varepsilon^{1 / 3}=(1-f) \varepsilon_{m}^{1 / 3}+f \varepsilon_{b}^{1 / 3} .
$$

Figure 1 also reports $\varepsilon^{\prime}$ and $\tan \delta$ for biochar, resulting from the application of Equation (1). The very high value of $\varepsilon^{\prime}$ for biochar is remarkable (note the log scale) and promising for shielding applications. This result was, in turn, used to calculate, by Equation (1), the complex permittivity of other composites, mixing the measured permittivity of various matrices (cement, HDPE) and the calculated permittivity of biochar. Finally, all these data allowed us to calculate the shielding efficiency, according to the approach described in the following paragraph.

\subsection{Electromagnetic Shielding Efficiency}

For an electromagnetic wave propagating into a material with negligible magnetic properties and under the far field conditions $(k r \gg 1$, where $k$ is the wave number and $r$ is the source-detector distance), the overall shielding efficiency $S E$ is expressed, in decibels $(\mathrm{dB})$, as [36,37]:

$$
S E=10 \log _{10}\left(\frac{P_{i}}{P_{t}}\right)=S E_{A}+S E_{R}+S E_{M R}
$$

where $P_{i}$ and $P_{t}$ are the incident and transmitted power, $S E_{A}, S E_{R}$, and $S E_{M R}$ are the absorption, reflection, and multiple-reflection contributions to the shielding efficiency, respectively (see the scheme reported in Figure 2),

$$
\begin{gathered}
S E_{A}=20 \alpha t \log _{10} e=8.686 \alpha t, \\
S E_{R}=20 \log _{10} \frac{|1+n|^{2}}{4|n|}, \\
S E_{M R}=20 \log _{10} \mid 1-\exp (-2 \gamma t) \frac{(1-n)^{2}}{(1+n)^{2} \mid}, \\
\alpha=\frac{2 \pi}{\lambda_{0}} \sqrt{\frac{\left|\varepsilon^{\prime}\right|\left(\sqrt{1+\tan ^{2} \delta} \mp 1\right)}{2}}, \\
n=\sqrt{\frac{\left|\varepsilon^{\prime}\right|\left(\sqrt{1+\tan ^{2} \delta}\right.}{2}+j \sqrt{\frac{\left|\varepsilon^{\prime}\right|\left(\sqrt{1+\tan ^{2} \delta} \mp 1\right)}{2}}},
\end{gathered}
$$

$t$ is the thickness of the shield, $\alpha$ is the attenuation constant (equal to the inverse of the skin depth), $n$ is the complex refractive index, $\gamma=(1+j) \alpha$ is the propagation constant, $\tan \delta=\frac{\varepsilon^{\prime \prime}}{\varepsilon^{\prime}}$, and upper and lower signs are for positive and negative $\varepsilon^{\prime}$, respectively. It should be noted that all these contributions to the SE are relevant when the thickness of the EM shield is smaller than the skin depth; otherwise, there is no thickness dependence. For the biochar composites investigated in this study, this condition is always satisfied (e.g., for an epoxy-biochar $25 \mathrm{wt}$ \% composite, at $5 \mathrm{GHz}$, the skin depth is $31 \mathrm{~mm}$ [24]). To be complete, it should also be mentioned that SE could be calculated with a similar setup directly from the measurement of the scattering parameters. However, in order to employ the mixing rule and estimate the properties of other composites, we are forced to work with physical parameters of the materials rather than properties of the particular sample/device. 


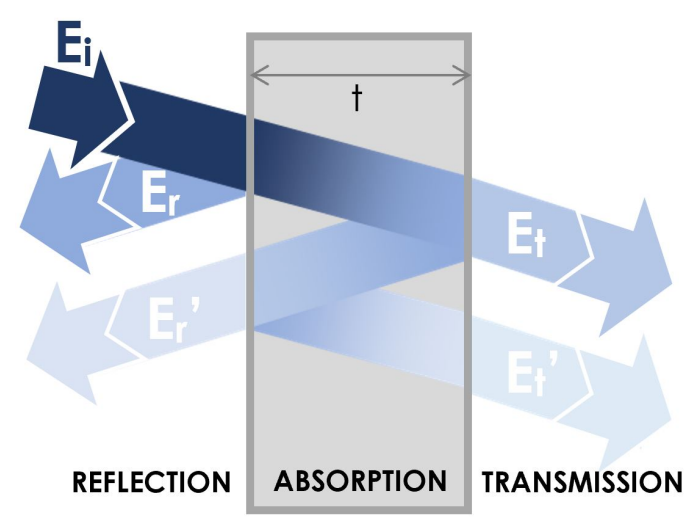

Figure 2. Mechanisms of attenuation of an electromagnetic radiation of energy $E_{i}$, incident on a shielding layer of thickness $t$ : reflection, multiple reflections, and absorption. $E_{r}\left(E_{t}\right)$ is the reflected (transmitted) energy, and $E_{r}{ }^{\prime}\left(E_{t}{ }^{\prime}\right)$ is the energy reflected (transmitted) after multiple crossing the layer. Color attenuation represents attenuation of energy.

Figure 3 shows the contribution of absorption, reflection, and multiple reflections to the shielding efficiency $S E$, in the case of biochar-epoxy shielding layers 10 or $30 \mathrm{~mm}$ thick, calculated starting from the experimental data shown in Figure 1. It can be noticed that the contribution of the multiple-reflections term can be positive or negative but, generally, negligible when $S E_{A} \geq 10 \mathrm{~dB}$.

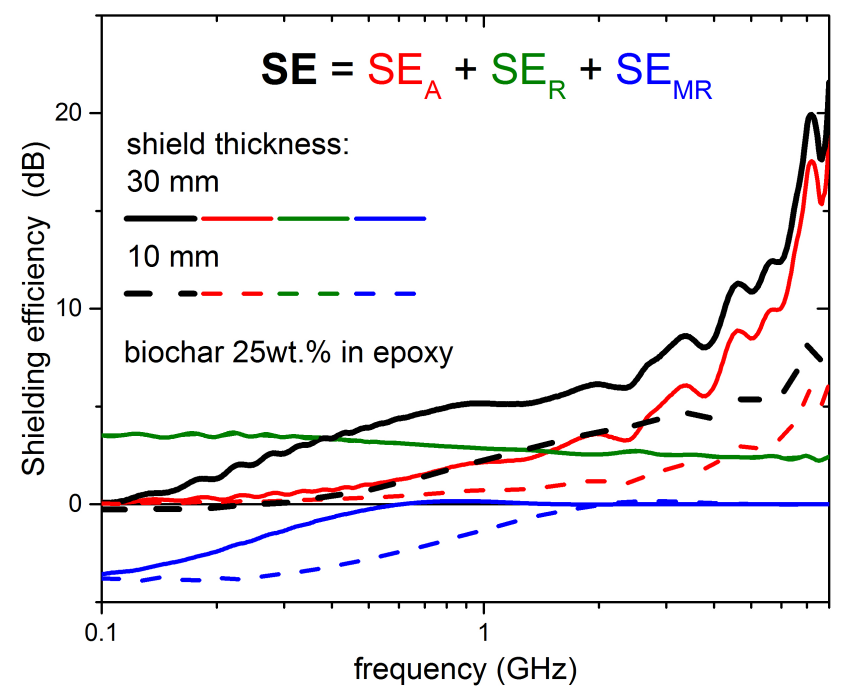

Figure 3. Absorption (A, shown in red), reflection (R, shown in green), and multiple reflections (MR, shown in blue) components of the overall shielding efficiency $S E$ (shown in black), for biochar-epoxy layers of thickness $10 \mathrm{~mm}$ and $30 \mathrm{~mm}$. SE was calculated from experimental data shown in Figure 1 (epoxy-25 wt.\%-biochar composite, with biochar treated at $1500^{\circ} \mathrm{C}$ ).

\section{Results and Discussion}

Biochar used as filler for this study was preliminary analyzed by using Raman and XRD spectroscopy, as reported in Figure 4. According to Ferrari et al. [38], the Raman spectra of disordered carbon could be a helpful tool for the evaluation of the disorder of carbonaceous material. In Figure 4, the Raman spectra of biochar used as filler in this work is reported, showing $D$ and $G$ peaks centered at $1347 \mathrm{~cm}^{-1}$ and $1574 \mathrm{~cm}^{-1}$, respectively, and the ratio between their areas (ID/IG) reaches up to 0.78 [29]. Furthermore, the $2 \mathrm{D}$ region is very well defined, suggesting the presence of a quite ordered material [39]. XRD spectra (Figure $4 \mathrm{~b}$ ) showed a broad band between $16^{\circ}$ to $32^{\circ}$ due to the presence of amorphous carbon with a narrow feature at $26^{\circ}$ due to the presence of graphite, and another broad signal between $42^{\circ}$ and $47^{\circ}$ due to the $\mathrm{sp}^{2}$ carbon network. According 
to previously reported data, biochar used as filler shows graphitic crystallites in-plane size of up to $2.3 \mathrm{~nm}$ with an inter-layer spacing of up to $0.344 \mathrm{~nm}$ very close to the one of the graphite $(0.355 \mathrm{~nm})$ [40]. These analyses clearly show a material not yet fully graphitized but presenting an appreciable amount of graphitic domains. As reported in Reference [41], the carbon structure of biochar treated at $1500{ }^{\circ} \mathrm{C}$ was characterized by a high conductivity and could be easily used to improve the conductivity of related composites. Most likely, this increased conductivity (given by a combination of migration and hopping conductance [25] promoted by the ordering of graphitic crystallites), together with interfacial polarization [42], is the main mechanism contributing to EM shielding in biochar composites at these frequencies [43].
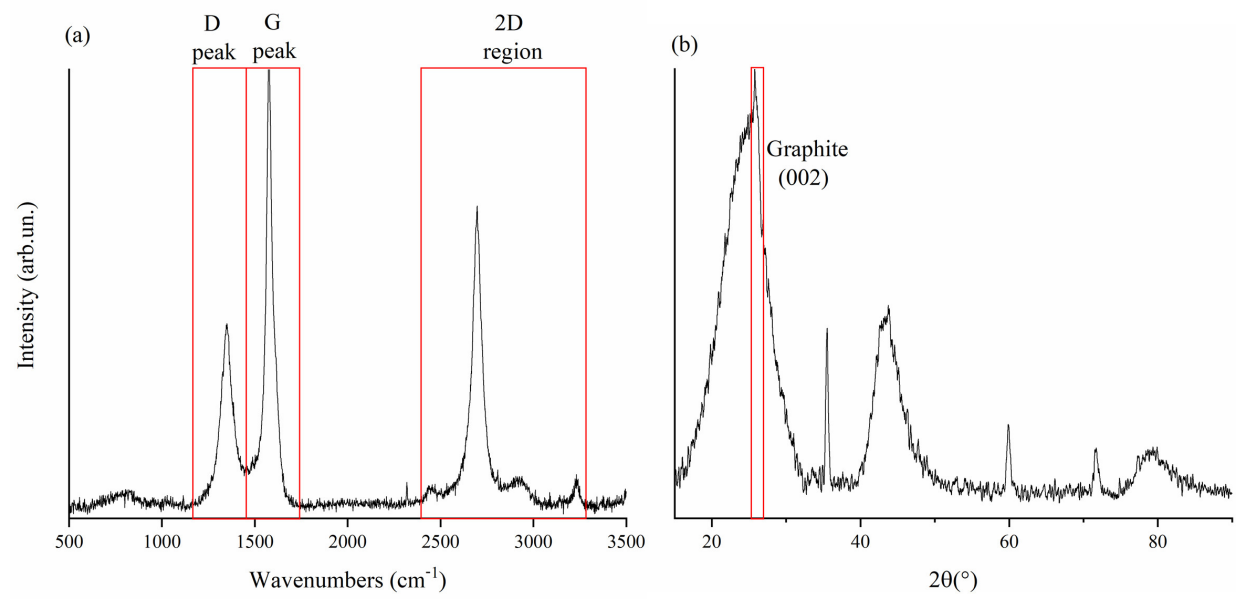

Figure 4. (a) Raman and (b) XRD spectra of biochar used as filler.

In Figure 5a-d, we report calculated $S E$ for various materials and biochar composites, of potential interest as building materials. Figure 5a shows the EM shielding capability of 30-mm-thick layers of silicon, epoxy, HDPE, and cement, obtained starting from direct microwave measurements. Cement shows a larger SE than other matrices, mostly due to a larger real part of the permittivity, with values close to 5 instead of $2-3$, whereas the $\tan \delta$ are comparable for all four materials. It is clear that none of the materials are able to reach, in the selected frequency range, a useful EM shielding level. On the contrary, the addition of biochar inclusions significantly improves the $S E$ performance. Figure $5 b$ shows the case of epoxy: the curves for biochar volume fraction $f=0.12$, and 0.2 have been calculated directly from experimental data, while the $f=0.3$ curve has been deduced from data of epoxy and biochar by the mixing rule formula. In Figure $5 c, d$, similar curves are shown for HDPE and cement, all calculated from data of blank material and biochar-composites by the mixing formula. As expected, the increase of both thickness and biochar content largely enhances the SE of the composites. The most efficient combinations are cement-based, due to the better performance of the matrix itself. However, since the main contribution to SE comes from the inclusions, the spread between different composites decreases with increasing filler content. Finally, in Figure 6, we report a summary of SE of composites at the frequencies of 5 and $7 \mathrm{GHz}$ (representatives of the $\mathrm{C}$ band), as a function of biochar volume fraction. $S E$ values of 10,20 , and $30 \mathrm{~dB}$ are also reported as horizontal lines, as a reference for application requirements. Clearly, such composites can be considered as a valid route to EM shielding, granting the possibility to achieve a desired SE by choosing the suitable matrix, filler content, and thickness. Particularly promising, from the point of view of decreased environmental impact, is the much smaller thickness and, therefore, overall material required by biochar-filled composites, with respect to non-added matrices, to achieve a certain SE. 

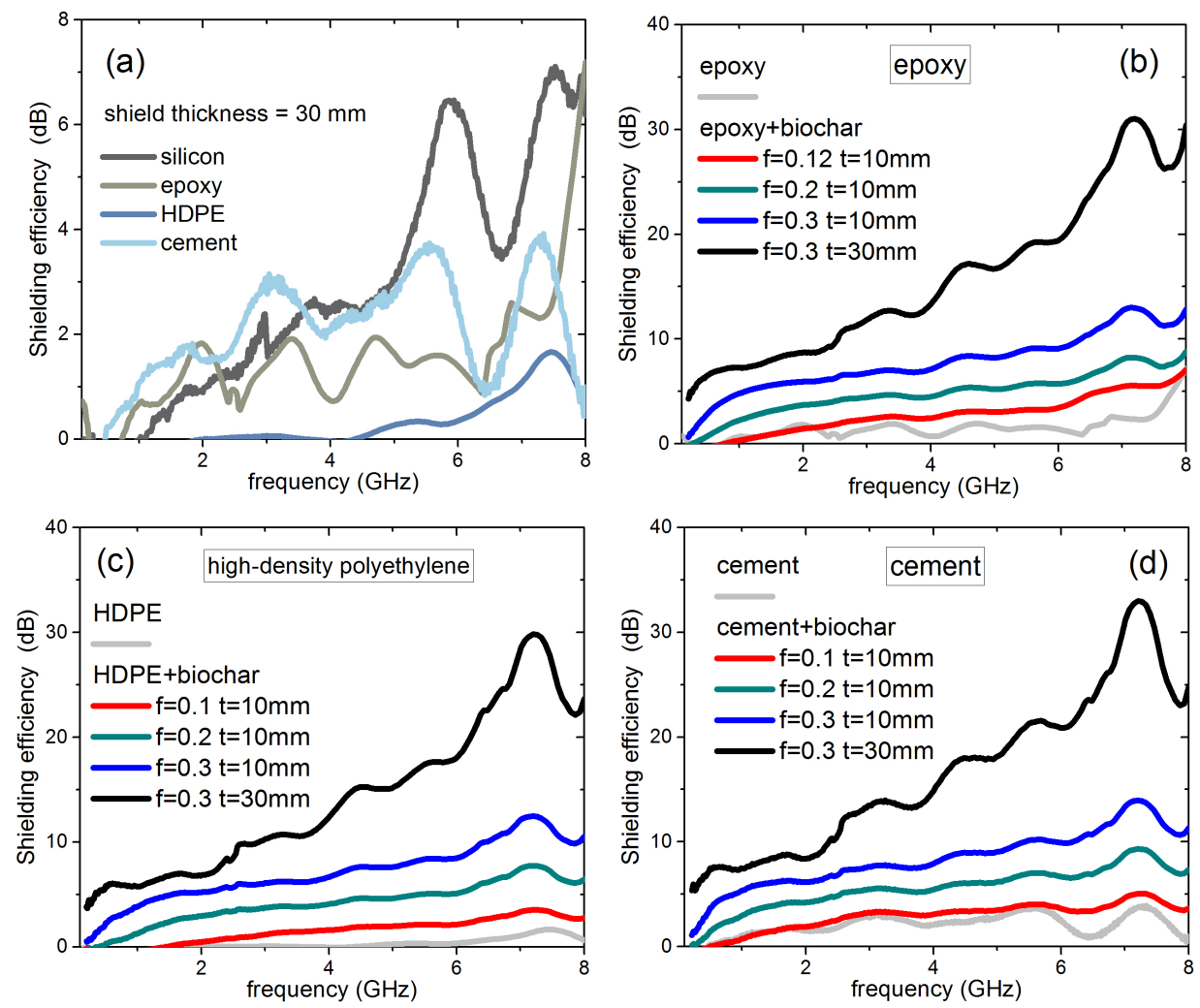

Figure 5. (a) Shielding efficiency of a 30-mm-thick uniform layer of different materials: silicon, epoxy, HDPE, and cement. (b) Shielding efficiency of a 30-mm-thick uniform layer of epoxy (light gray), of 10-mm-thick epoxy-biochar layers, with different biochar volume fractions (from $f=0.12$, red, to $f=0.3$, blue), and of a shield with thickness $30 \mathrm{~mm}$ and $f=0.3$ (black). (c,d): same as (b), but for HDPE and cement.

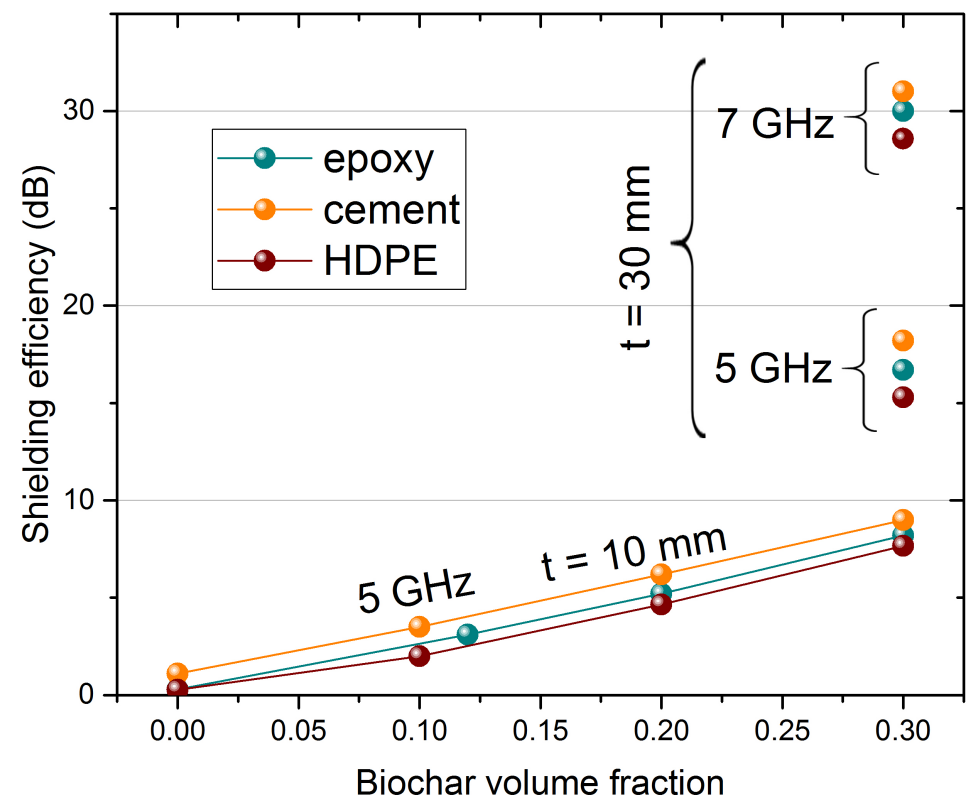

Figure 6. Shielding efficiency for different composites as a function of biochar volume fraction, at the frequencies of 5 and $7 \mathrm{GHz}$ for 10-mm-thick and 30-mm-thick shields. Reference $S E$ values are marked by horizontal gray lines, at 10, 20, and $30 \mathrm{~dB}$, corresponding to $90 \%, 99 \%$, and $99.9 \%$ of shielded EM power, respectively. 


\section{Conclusions}

In conclusion, we investigated the microwave shielding efficiency of composites, where biochar inclusions are dispersed in materials of interest for building construction. We directly measured raw materials and some biochar composites, obtaining their complex permittivity in the range from $100 \mathrm{MHz}$ to $8 \mathrm{GHz}$. Then, we extracted the biochar contribution and calculated the properties of other composite combinations by a suitable permittivity mixing formula. From complex permittivity, finally, we calculated the shielding efficiency, showing that tailoring the content of biochar-a cost-effective and ecofriendly material —and layer thickness allows obtaining a desired value of EM shielding, among those significant for applications. Moreover, annealed biochar properties could be further improved by selecting low inorganic content feedstocks, that would guarantee an improvement of graphitic domains in terms of size and ordering. In addition, the addition of metallic particles could be a viable approach to further increase the SE, in light of the fact that, in the case of biochar, these species could be anchored directly to the filler surface though carbothermal processes. Finally, this mixed experimental and computational approach represents a quick and cost-effective way to explore new solutions for EM shielding and materials optimization in the construction field.

Author Contributions: Conceptualization, G.G. and D.T.; investigation, D.T., M.B., and G.G.; visualization, discussion, and writing, all authors. All authors have read and agreed to the published version of the manuscript.

Funding: This research received no external funding.

Conflicts of Interest: The authors declare that they have no known competing financial interests or personal relationships that could have appeared to influence the work reported in this paper.

\section{References}

1. Guan, H.; Liu, S.; Duan, Y.; Cheng, J. Cement based electromagnetic shielding and absorbing building materials. Cem. Concr. Compos. 2006, 28, 468-474. [CrossRef]

2. Yasir, M.; di Summa, D.; Ruscica, G.; Natali Sora, I.; Savi, P. Shielding Properties of Cement Composites Filled with Commercial Biochar. Electronics 2020, 9, 819. [CrossRef]

3. Wen, S.; Chung, D. Partial replacement of carbon fiber by carbon black in multifunctional cement-matrix composites. Carbon 2007, 45, 505-513. [CrossRef]

4. Gibson, R.F. A review of recent research on mechanics of multifunctional composite materials and structures. Compos. Struct. 2010, 92, 2793-2810. [CrossRef]

5. Vaessen, W.; Dyk, J. RF Shielding Due to Building Structures Like Brick Walls, Wire Grids and Metal Coated Windows. In Proceedings of the 1988 18th European Microwave Conference, Stockholm, Sweden, 12-15 September 1988; pp. 625-631.

6. Sato, N. Some concepts of corrosion fundamentals. Corros. Sci. 1987, 27, 421-433. [CrossRef]

7. Kong, L.; Yin, X.; Xu, H.; Yuan, X.; Wang, T.; Xu, Z.; Huang, J.; Yang, R.; Fan, H. Powerful absorbing and lightweight electromagnetic shielding CNTs/RGO composite. Carbon 2019, 145, 61-66. [CrossRef]

8. Singh, A.K.; Shishkin, A.; Koppel, T.; Gupta, N. A review of porous lightweight composite materials for electromagnetic interference shielding. Compos. Part B Eng. 2018, 149, 188-197. [CrossRef]

9. Novais, R.M.; Saeli, M.; Caetano, A.P.; Seabra, M.P.; Labrincha, J.A.; Surendran, K.P.; Pullar, R.C. Pyrolysed cork-geopolymer composites: A novel and sustainable EMI shielding building material. Constr. Build. Mater. 2019, 229, 116930. [CrossRef]

10. Bartoli, M.; Giorcelli, M.; Jagdale, P.; Rovere, M.; Tagliaferro, A. A review of non-soil biochar applications. Materials 2020, $13,261$. [CrossRef] [PubMed]

11. González, M.; Pozuelo, J.; Baselga, J. Electromagnetic Shielding Materials in GHz Range. Chem. Rec. 2018, 18, 1000-1009. [CrossRef]

12. Chung, D. Electromagnetic interference shielding effectiveness of carbon materials. Carbon 2001, 39, 279-285. 10.1016/S00086223(00)00184-6. [CrossRef]

13. Al-Saleh, M.H.; Saadeh, W.H.; Sundararaj, U. EMI shielding effectiveness of carbon based nanostructured polymeric materials: A comparative study. Carbon 2013, 60, 146-156. [CrossRef]

14. Das, N.; Khastgir, D.; Chaki, T.; Chakraborty, A. Electromagnetic interference shielding effectiveness of carbon black and carbon fibre filled EVA and NR based composites. Compos. Part A Appl. Sci. Manuf. 2000, 31, 1069-1081. [CrossRef]

15. Munalli, D.; Dimitrakis, G.; Chronopoulos, D.; Greedy, S.; Long, A. Electromagnetic shielding effectiveness of carbon fibre reinforced composites. Compos. Part B Eng. 2019, 173, 106906. [CrossRef] 
16. Park, G.; Kim, S.; Park, G.K.; Lee, N. Influence of carbon fiber on the electromagnetic shielding effectiveness of high-performance fiber-reinforced cementitious composites. J. Build. Eng. 2021, 35, 101982. [CrossRef]

17. Savi, P.; Yasir, M.; Bartoli, M.; Giorcelli, M.; Longo, M. Electrical and Microwave Characterization of Thermal Annealed Sewage Sludge Derived Biochar Composites. Appl. Sci. 2020, 10, 1334. [CrossRef]

18. Li, S.; Huang, A.; Chen, Y.J.; Li, D.; Turng, L.S. Highly filled biochar/ultra-high molecular weight polyethylene/linear low density polyethylene composites for high-performance electromagnetic interference shielding. Compos. Part B Eng. 2018, 153, 277-284. [CrossRef]

19. Che, R.; Peng, L.M.; Duan, X.; Chen, Q.; Liang, X. Microwave Absorption Enhancement and Complex Permittivity and Permeability of Fe Encapsulated within Carbon Nanotubes. Adv. Mater. 2004, 16, 401-405. [CrossRef]

20. Liu, Q.; Cao, Q.; Bi, H.; Liang, C.; Yuan, K.; She, W.; Yang, Y.; Che, R. CoNi@SiO2@TiO2 and CoNi@Air@TiO2 Microspheres with Strong Wideband Microwave Absorption. Adv. Mater. 2016, 28, 486-490. [CrossRef]

21. Cao, M.S.; Wang, X.X.; Zhang, M.; Shu, J.C.; Cao, W.Q.; Yang, H.J.; Fang, X.Y.; Yuan, J. Electromagnetic Response and Energy Conversion for Functions and Devices in Low-Dimensional Materials. Adv. Funct. Mater. 2019, 29, 1807398. [CrossRef]

22. Cao, M.S.; Wang, X.X.; Zhang, M.; Cao, W.Q.; Fang, X.Y.; Yuan, J. Variable-Temperature Electron Transport and Dipole Polarization Turning Flexible Multifunctional Microsensor beyond Electrical and Optical Energy. Adv. Mater. 2020, 32, 1907156. [CrossRef]

23. Cao, M.; Wang, X.; Cao, W.; Fang, X.; Wen, B.; Yuan, J. Thermally Driven Transport and Relaxation Switching Self-Powered Electromagnetic Energy Conversion. Small 2018, 14, 1800987. [CrossRef]

24. Torsello, D.; Ghigo, G.; Giorcelli, M.; Bartoli, M.; Rovere, M.; Tagliaferro, A. Tuning the microwave electromagnetic properties of biochar-based composites by annealing. Carbon Trends 2021, 4, 100062. [CrossRef]

25. Cao, M.S.; Song, W.L.; Hou, Z.L.; Wen, B.; Yuan, J. The effects of temperature and frequency on the dielectric properties, electromagnetic interference shielding and microwave-absorption of short carbon fiber/silica composites. Carbon 2010, 48, 788796. [CrossRef]

26. Wen, B.; Cao, M.; Lu, M.; Cao, W.; Shi, H.; Liu, J.; Wang, X.; Jin, H.; Fang, X.; Wang, W.; et al. Reduced Graphene Oxides: LightWeight and High-Efficiency Electromagnetic Interference Shielding at Elevated Temperatures. Adv. Mater. 2014, 26, 3484-3489. [CrossRef]

27. Mašek, O.; Buss, W.; Roy-Poirier, A.; Lowe, W.; Peters, C.; Brownsort, P.; Mignard, D.; Pritchard, C.; Sohi, S. Consistency of biochar properties over time and production scales: A characterisation of standard materials. J. Anal. Appl. Pyrolysis 2018, 132, 200-210. [CrossRef]

28. Arrigo, R.; Bartoli, M.; Torsello, D.; Ghigo, G.; Malucelli, G. Thermal, dynamic-mechanical and electrical properties of UV-LED curable coatings containing porcupine-like carbon structures. Mater. Today Commun. 2021, 28, 102630. [CrossRef]

29. Tagliaferro, A.; Rovere, M.; Padovano, E.; Bartoli, M.; Giorcelli, M. Introducing the Novel Mixed Gaussian-Lorentzian Lineshape in the Analysis of the Raman Signal of Biochar. Nanomaterials 2020, 10, 1748. [CrossRef] [PubMed]

30. Bartoli, M.; Giorcelli, M.; Rosso, C.; Rovere, M.; Jagdale, P.; Tagliaferro, A. Influence of Commercial Biochar Fillers on Brittleness/Ductility of Epoxy Resin Composites. Appl. Sci. 2019, 9, 3109. [CrossRef]

31. Ba, D.; Sabouroux, P. Epsimu, a toolkit for permittivity and permeability measurement in microwave domain at real time of all materials: Applications to solid and semisolid materials. Microw. Opt. Technol. Lett. 2010, 52, 2643-2648. [CrossRef]

32. Nicolson, A.; Ross, G. Measurement of the intrinsic properties of materials by time-domain techniques. IEEE Trans. Instrum. Meas. 1970, 19, 377-382. [CrossRef]

33. Baker-Jarvis, J.; Vanzura, E.J.; Kissick, W.A. Improved technique for determining complex permittivity with the transmission/reflection method. IEEE Trans. Microw. Theory Tech. 1990, 38, 1096-1103. [CrossRef]

34. Looyenga, H. Dielectric constants of heterogeneous mixtures. Physica 1965, 31, 401-406. [CrossRef]

35. Yang, R.B.; Hsu, S.D.; Lin, C.K. Frequency-dependent complex permittivity and permeability of iron-based powders in 2-18 GHz. J. Appl. Phys. 2009, 105, 07A527. [CrossRef]

36. Joo, J.; Epstein, A. Electromagnetic radiation shielding by intrinsically conducting polymers. Appl. Phys. Lett. 1994, 65, 2278-2280. [CrossRef]

37. Jackson, J.D. Classical Electrodynamics; Wiley: New York, NY, USA, 1974.

38. Ferrari, A.C.; Robertson, J. Interpretation of Raman spectra of disordered and amorphous carbon. Phys. Rev. B 2000, 61, 1409514107. [CrossRef]

39. Lee, Y.J. The second order Raman spectroscopy in carbon crystallinity. J. Nucl. Mater. 2004, 325, 174-179. j.jnucmat.2003.12.005. [CrossRef]

40. Jeong, H.K.; Noh, H.J.; Kim, J.Y.; Jin, M.H.; Park, C.Y.; Lee, Y.H. X-ray absorption spectroscopy of graphite oxide. EPL Europhys. Lett. 2008, 82, 67004. [CrossRef]

41. Giorcelli, M.; Bartoli, M.; Sanginario, A.; Padovano, E.; Rosso, C.; Rovere, M.; Tagliaferro, A. High-Temperature Annealed Biochar as a Conductive Filler for the Production of Piezoresistive Materials for Energy Conversion Application. ACS Appl. Electron. Mater. 2021, 3, 838-844. [CrossRef]

42. Zhao, H.; Cheng, Y.; Liu, W.; Yang, L.; Zhang, B.; Wang, L.P.; Ji, G.; Xu, Z.J. Biomass-derived porous carbon-based nanostructures for microwave absorption. Nano-Micro Lett. 2019, 11, 1-17. [CrossRef]

43. Hashisho, Z.; Rood, M.J.; Barot, S.; Bernhard, J. Role of functional groups on the microwave attenuation and electric resistivity of activated carbon fiber cloth. Carbon 2009, 47, 1814-1823. [CrossRef] 